\title{
Contextual differences in student motivation and self-regulated learning in mathematics, English, and social studies classrooms*
}

\author{
CHRISTOPHER A. WOLTERS ${ }^{1}$ \& PAUL R. PINTRICH ${ }^{2}$ \\ ${ }^{1}$ Department of Educational Psychology University of Houston; ${ }^{2}$ Combined Program in \\ Education and Psychology University of Michigan, Ann Arbor, U.S.A.
}

\begin{abstract}
Recent research on self-regulated learning has stressed the importance of both motivational and cognitive components of classroom learning. Much of this research has examined these components without consideration of potential contextual differences. Using a within-subject correlational design, the present study assessed mean level differences in students' task value, self-efficacy, test anxiety, cognitive strategy use, regulatory strategy use, and classroom academic performance by gender and across the subject areas of mathematics, social studies, and English. In addition, the relations among the motivational, strategy use, and performance measures were assessed using multivariate regressions. The participants were 545 seventh and eighth grade students ( $51 \%$ females) who responded to a self-report questionnaire. Results revealed mean level differences by subject area and gender in the motivation and cognitive strategy use variables, but not in regulatory strategy use or academic performance. In contrast, results indicated that the relations among these constructs was very similar across the three subject areas examined. Findings are discussed in terms of their importance for understanding the contextual nature of students' self-regulated learning.
\end{abstract}

Recent research on student academic performance has stressed the importance of considering both motivational and cognitive components of classroom learning. Although there are a number of important motivational components, three have been linked consistently to self-regulated learning, including beliefs about one's efficacy to do classroom tasks, value for these tasks, and anxiety (Pintrich \& De Groot, 1990; Pintrich, Roeser \& De Groot, 1994; Pintrich \& Schrauben, 1992). Two general cognitive components seem to be most important in this research, including cognitive strategies designed to increase encoding, retention, and comprehension of classroom material as well as various metacognitive and regulatory strategies that help students

* An earlier version of this paper was presented at the European Association for Research on Learning and Instruction, Nijmegen, The Netherlands, August 1995. The data reported on in this article are part of the Competence and Commitment Project conducted at The Combined Program in Education and Psychology at the University of Michigan. We thank our colleagues on this project including Eric Anderman, Anastasia Danos Elder, Teresa Garcia, Lynley Hicks, Barbara Hofer, Helen Patrick, Allison Ryan, Tim Urdan, and Shirley Yu. 
monitor and control their own learning (Corno, 1989; Sternberg, 1988; Weinstein \& Mayer, 1986; Zimmerman, 1989).

Models of self-regulated learning strive to integrate these different motivational and cognitive components into a comprehensive model of students' classroom academic performance (Garcia \& Pintrich, 1994; Zimmerman, 1994). However, most of these models assume that self-regulated learning is a relatively general process that operates in the same fashion across different domains or situations. Very little empirical research has examined how the various components of self-regulated learning may vary as a function of contextual differences. The present study seeks to address this gap in the literature by examining components of motivation and cognition across three different academic subjects using a within-subject design. In particular, the purpose of this study was to examine whether students' level of motivation and cognition varies across domains and if the relations between the motivational and cognitive components of self-regulated learning change as a function of the three domains.

Many motivational processes are thought to be sensitive to features of the task, the classroom, or the context within which a student is engaged. For example, self-efficacy is usually described as being task-specific (Bandura, 1986; Schunk, 1989, 1991) as well as a vital process involved in general selfregulation (Schunk, 1994). In this model, students are thought to generate efficacy judgments for specific classroom tasks and it is assumed that these beliefs will vary as a function of task or classroom features (Pintrich \& Schunk, 1996). Task value is usually conceptualized as personal characteristics of the individual in expectancy-value models of motivation (Eccles, 1983; Wigfield, 1994). At the same time, these models assume that individuals will find different domains (i.e., mathematics vs. English) as more or less personally interesting or valued (Wigfield, 1994; Wigfield \& Eccles, 1992, 1994). Accordingly, the level of task value should differ as a function of the domain. Anxiety is also viewed as an individual difference variable that may vary by domain with some individuals having more anxiety for a particular domain such as mathematics (e.g., Wigfield \& Eccles, 1989). In sum, the levels of each of these motivational components are assumed to depend on features of the task or domain.

The research on the cognitive components suggests these factors also may vary as a function of the task or domain. For example, research on cognitive strategies has found that strategies may not transfer across situations in that the use of cognitive strategies often seems to be dependent on environmental cues and the features of the tasks (Brown, Bransford, Ferrara \& Campione, 1983; Schneider \& Pressley, 1989). At the same time, however, there are individual differences in students' knowledge and use of cognitive strategies (Siegler, 
1988; Sternberg, 1988, 1994) that seem to transcend contextual features. In addition, if the use of cognitive strategies is related to motivational beliefs, as it seems to be (see Pintrich \& Schrauben, 1992 for review), then when the level of motivational beliefs vary by domain, it would be expected that the level of cognitive strategy use would also vary.

A similar argument can be made for variations in the use of self-regulation strategies by domains or situations. In some cases, the process of selfregulation has been described as more independent of contextual influences. Self-regulating students are assumed to be aware of and able to control their actions in order to reach learning goals and an important aspect of this awareness and control is the ability to overcome contextual difficulties (Corno, 1989; Zimmerman \& Martinez-Pons, 1990). This ability to overcome problems would include the power to create one's own goals for a learning situation, to muster motivation for that goal, and to enact the cognitive resources necessary to reach the goal. Self-regulated learners are able to avoid or conquer obstacles that obstruct their learning goals. Past research on self-regulation has reflected this view by examining self-regulation within a particular context (Pintrich \& De Groot, 1990) or without reference to any specific context (Zimmerman \& Martinez-Pons, 1990). This view would suggest that there may not be variations in self-regulation by context.

In apparent opposition to this view, Zimmerman (1994) suggests that the nature of the classroom context plays an important role in facilitating selfregulating learning. Classrooms that do not allow for much choice or control in use of time, choice of strategies to perform tasks, or even which tasks to perform, limit the opportunities for the development and use of self-regulatory strategies. In addition, classroom studies have shown that differences in teachers' instructional methods, including the type of task in which they ask students to engage, can influence the motivational goals that students adopt for their learning as well as their self-regulated learning (Ames, 1992; Maehr \& Midgley, 1991). More generally, work on academic tasks (e.g., Doyle, 1983; Meece, Blumenfeld \& Hoyle, 1988) and research on the nature of the classroom participation structures (Cohen, 1994) has provided evidence that the activities students participate in can have an important impact on students' motivation and level of self-regulated learning in the classroom.

Most of these classroom studies, however, have not examined subject area or disciplinary differences in these classroom features. Although the contextual differences among classrooms of different academic disciplines may not seem pronounced, there is evidence that significant differences exist among teachers and classrooms representing different academic subjects. For example, it seems that secondary teachers from different subject areas (mathematics, science, social studies, English, and foreign languages) have 
different views of the nature of the discipline they teach and that these views relate to different instructional beliefs and practices (Grossman \& Stodolsky, 1994, 1995; Stodolsky \& Grossman, 1995). This research has found that mathematics and foreign language teachers believed that their subject areas were more defined, sequential, and static, while science, social studies, and English teachers perceived their subject areas as more open, less sequential, and more dynamic. This suggests that mathematics classrooms may provide less opportunity for self-regulated learning if Zimmerman's (1994) claims are correct regarding constraints that might be operating on opportunities for self-regulated learning in many traditional classrooms. In support of this argument, Stodolsky (1988) found differences between mathematics and social studies lessons in fifth grade classrooms including differences in the nature of instruction and the types of tasks assigned to students. She found that mathematics instruction was more structured, sequential, and less engaging than social studies lessons and that mathematics tasks were often of less cognitive complexity than the variety and diversity found in the social studies tasks. She also found that student involvement, basically measured by an observer's dichotomous rating of "on-task" or "off-task", was higher when cognitive complexity of the task was high. However, this type of observational data did not address the quality of student cognitive engagement in terms of self-regulated learning or motivation. In this study, we will address this gap in the empirical literature by using students' self-reports of their cognition and motivation in the different subject areas.

In research that has focused on students' motivational beliefs for different subject areas, Eccles and Wigfield and their colleagues have consistently found differences between English and mathematics classrooms in elementary through secondary classrooms. The consistent pattern is that students' expectancies or efficacy beliefs, task value and interest, and anxiety are generally less positive and less adaptive in mathematics classrooms than in English classrooms (Eccles, 1983, 1984; Wigfield, 1994; Wigfield \& Eccles, 1992, 1994). However, they have not examined other subject areas in their research, nor have they investigated students' cognitive engagement in terms of self-regulated learning. Stodolsky, Salk \& Glaessner (1991) found that fifth graders' beliefs about mathematics were more likely to be tied to their ability to do the work, while social studies beliefs were related to interest in the activities. Given these results, it seems important to examine students' motivational beliefs and self-regulated learning in different subject areas.

In addition, differences between disciplines may be more pronounced for some groups of students in comparison to other groups. For example, there is a fair amount of research that suggests there are stable gender differences in males' and females' motivation for mathematics and English courses. 
Eccles and Wigfield and their colleagues report that males have higher selfcompetence or efficacy beliefs for mathematics, while females have higher efficacy beliefs for English. They did not find differences in task value beliefs in mathematics, but females had higher value beliefs for English (Eccles, 1983, 1984; Eccles, Wigfield, Flanagan, Miller, Reuman \& Yee, 1989; Wigfield, Eccles, MacIver, Reuman \& Midgley, 1991; Wigfield \& Eccles, 1994). In addition, research on self-regulation has found differences in the amount of self-regulation behavior reported by males and females with females showing higher levels of self-regulated learning (Zimmerman \& Martinez-Pons, 1990). Thus, when considering subject area differences in student motivation and cognition, it is important to examine how these differences might interact with gender.

In summary, three basic questions were addressed in this study. First, are there differences in the students' level of motivation and self-regulated learning for the subject areas of mathematics, social studies, and English? Motivation is defined in terms of self-efficacy, task value, and anxiety, whereas self-regulated learning is defined in terms of students' cognitive and regulatory strategy use. Based on previous theoretical characterizations and classroom studies of self-efficacy and task value, it was expected that students would report greater levels of self-efficacy and task value in English and social studies than in mathematics (Eccles, 1983, 1984; Stodolsky, 1988; Wigfield, 1994; Wigfield \& Eccles, 1992, 1994). Consistent with the anticipated differences in students' motivation, and following Stodolsky's (1988) finding that mathematics instruction was more structured, sequential, less engaging and consisted of less complex tasks than social studies lessons, it was predicted that students would report greater levels of cognitive and regulatory strategy use in social studies, and perhaps English, than in mathematics. In sum, the overall expectation was that students would report a more adaptive motivational and cognitive profile in English and social studies than in mathematics.

A second major research question was, do the relations between these motivational and self-regulated learning constructs vary as a function of subject area? With regard to this question it was predicted that the relation between the motivational, cognitive and achievement factors would be similar across the three subject areas examined. In other words, whereas the level of students' motivation and/or cognitive or regulatory strategy use was predicted to vary across domains, the relations between the motivational and cognitive components was predicted to remain stable. Regardless of subject area, higher levels of task value and self-efficacy were predicted to lead to greater cognitive and regulatory strategy use, whereas higher levels of anxiety were predicted to be negatively related to cognitive and regulatory strategy use. 
The final research question was, does gender have a main or interactive effect on students' motivation and cognition in these three different subject areas? Consistent with previous studies by Eccles and her colleagues (e.g., Eccles, 1983; Eccles et al., 1989) it was predicted that the pattern of mean level differences among the three subjects examined would be different for males and females. Specifically, it was predicted males would report higher efficacy beliefs in mathematics, whereas females would report higher efficacy beliefs in English. Further, based on the work of Zimmerman \& MartinezPons (1990) it was predicted that females would report higher levels of self-regulation than males.

\section{Method}

\section{Participants}

Participants for the study were 545 seventh and eighth grade students from a junior high school (7-9th grades) in a working class suburb of a midwestern city. There were slightly more females $(n=280,51 \%)$, than males $(n=265$, $49 \%$ ) in the sample. Ages ranged from 11 to 15 years, with an overall mean age of 12.6 years $(S D=0.66)$. The majority of subjects $(95 \%)$ were Caucasian. Seventh and eighth grade students present in school the day and class period that questionnaires were administered participated in the study. However, only students who had valid data for all of the outcome measures were included in the present analyses. All participants were enrolled in mathematics, English, and social studies. There were six teachers for mathematics, six teachers for English, and five teachers for social studies. None of the teachers in the study taught more than one subject area.

\section{Measures}

Motivation and cognition. Students completed a self-report questionnaire adapted from Pintrich \& De Groot (1990) and Pintrich, Smith, Garcia \& McKeachie (1993) that assessed different facets of student motivation and cognition, including the three motivational beliefs of task value, self-efficacy, and test anxiety and the two cognitive components of cognitive and selfregulatory strategy use. The questionnaire used in this study was different from earlier versions in two ways. First, the current questionnaire included only a subset of all the scales represented on previously-published forms of the Motivated Strategies for Learning Questionnaire (Pintrich, et al. 1993). Second, items on the current questionnaire were selected and/or adapted to 
reflect better the academic behaviors and experiences of the age group examined. For example, a cognitive strategy use item which referred to underlining important ideas in the textbook was dropped because students in this age group typically do not buy their textbooks and are expected to keep them free of marks. On this questionnaire, students were presented with an item and then asked to respond to the item once for each of four different subject areas including mathematics, English, social studies, and science. ${ }^{1}$ Students responded to each item using a seven point Likert scale from (1) "Not at all like me" to (7) "Very much like me".

For this study, the task value scale was composed of nine items that assessed students' instrumental value and interest for the material studied within each subject. Students scoring high on this scale viewed the material within a particular subject as personally useful, interesting, and important. Coefficient alphas for the three subject areas ranged from 0.77 to 0.83 . The self-efficacy scale included 4 items that assessed students' beliefs about how capable they were of doing the work within each subject area ( $\alpha$ 's $=0.80$ to 0.84$)$. Students high on this scale were sure they could learn and understand the material being taught in the class and perform well in the class. The four test anxiety items asked students about affective and physical symptoms of anxiety during tests $(\alpha$ 's $=0.75$ to 0.80$)$. Higher scores on this scale reflected greater anxiety associated with tests and classroom performance. The cognitive strategy use scale included nine items that asked students about their use of different learning strategies ( $\alpha$ 's $=0.86$ to 0.87 ) such as rehearsal and elaboration, whereas the seven self-regulation items asked students about strategies they might use to plan, monitor and control their learning ( $\alpha$ 's $=0.69$ to 0.70 ). Higher scores on these two scales meant that students reported engaging in these strategies more often than students with lower scores on these scales.

Classroom academic performance. Classroom performance was measured using teacher reported grades. These grades were assigned by the teachers approximately three months after the questionnaire data were collected but reflected performance throughout the semester. Marks were converted from letter grades to a thirteen point scale with "A+" being equal to 12 and " $F$ " being equal to a 0 . In order to minimize teacher effects and differences in grading patterns, classroom grades were standardized within teachers before completing analyses.

\section{Procedures}

Students were administered questionnaires in late October. Questionnaires primarily were administered to students during their mathematics and English class periods by members of the research team. In all classes, a brief set of 
directions, including practice questions, was read aloud, and any questions by the students addressed. Next, all items on the particular questionnaire were read aloud while students followed along and circled their responses in individual test booklets. Classroom grades were collected using official school records at the end of the semester.

\section{Analyses}

The first purpose of this paper was to investigate subject area differences in the motivational, cognitive, and academic performance variables. These differences were examined using a repeated measures analysis of variance for each of the six outcome measures described above with subject area as a repeated measures factor. In addition, gender was included as a between subjects factor given our third research question. Multivariate results from these 3 (subject area) by 2 (gender) ANOVAs were used to check for the main effects of subject area, gender, and for a subject area by gender interaction. All significant subject area, or subject area by gender effects then were followed-up using univariate Scheffe confidence intervals. In the presence of an interaction, these post hoc tests were calculated separately for males and females.

After these mean level analyses, we performed analyses designed to investigate our second question concerning the relations among the motivational, cognitive, and performance variables. First, we present the zero-order correlations among each of the six variables within each subject area. Second, we present results from a series of multivariate regressions using the motivational variables and gender to predict the cognitive strategy use, regulatory strategy use, and performance outcomes in mathematics, English, and social studies.

\section{Results}

\section{Subject area differences in mean level}

The overall mean scores for each of the outcome measures, as well as the mean scores for both males and females separately, are presented in Table 1. Results from the repeated measures ANOVAs and appropriate follow-up tests are reported first for the motivational variables, then for the two cognitive variables, and finally for students' classroom performance.

Task value. First, we examined students' value for the tasks in different academic subjects. Results indicated a main effect of subject, $F(2,542)=$ $16.22, p<0.001$, no main effect of gender, $F(1,543)=0.01, p>0.10$, and 
Table 1. Descriptive statistics for the motivational, strategy use and performance variables in mathematics, English and social studies for total sample and gender.

\begin{tabular}{|c|c|c|c|c|c|c|}
\hline \multirow[b]{2}{*}{ Variable } & \multicolumn{2}{|c|}{ Males } & \multicolumn{2}{|c|}{ Females } & \multicolumn{2}{|c|}{ Total } \\
\hline & $\mathrm{M}$ & SD & $\mathrm{M}$ & SD & $\mathrm{M}$ & SD \\
\hline \multicolumn{7}{|l|}{ Task Value } \\
\hline Mathematics & 5.51 & 1.06 & 5.51 & 1.10 & 5.51 & 1.08 \\
\hline English & 5.32 & 1.08 & 5.37 & 1.16 & 5.34 & 1.12 \\
\hline Social studies & 5.35 & 1.25 & 5.11 & 1.26 & 5.23 & 1.26 \\
\hline \multicolumn{7}{|l|}{ Self-efficacy } \\
\hline Mathematics & 5.59 & 1.15 & 5.36 & 1.23 & 5.47 & 1.20 \\
\hline English & 5.64 & 1.09 & 5.71 & 1.03 & 5.67 & 1.06 \\
\hline Social studies & 5.54 & 1.21 & 5.33 & 1.28 & 5.43 & 1.25 \\
\hline \multicolumn{7}{|l|}{ Test anxiety } \\
\hline Mathematics & 3.25 & 1.58 & 3.67 & 1.64 & 3.47 & 1.62 \\
\hline English & 3.13 & 1.51 & 3.26 & 1.41 & 3.19 & 1.46 \\
\hline Social studies & 3.40 & 1.65 & 4.04 & 1.62 & 3.73 & 1.66 \\
\hline \multicolumn{7}{|c|}{ Cognitive strategy use } \\
\hline Mathematics & 5.18 & 1.19 & 5.38 & 1.14 & 5.28 & 1.17 \\
\hline English & 5.22 & 1.17 & 5.45 & 1.12 & 5.34 & 1.15 \\
\hline Social studies & 5.34 & 1.13 & 5.54 & 1.15 & 5.44 & 1.14 \\
\hline \multicolumn{7}{|c|}{ Regulatory strategy use } \\
\hline Mathematics & 4.97 & 1.04 & 4.94 & 1.16 & 4.95 & 1.10 \\
\hline English & 4.96 & 1.07 & 4.99 & 1.14 & 4.98 & 1.10 \\
\hline Social studies & 5.00 & 1.08 & 4.91 & 1.17 & 4.95 & 1.12 \\
\hline \multicolumn{7}{|l|}{ Performance } \\
\hline Mathematics & -0.01 & 0.95 & 0.15 & 0.96 & 0.07 & 0.96 \\
\hline English & -0.05 & 0.97 & 0.20 & 0.86 & 0.08 & 0.92 \\
\hline Social studies & 0.01 & 0.92 & 0.16 & 0.94 & 0.08 & 0.93 \\
\hline
\end{tabular}

Note. Total $N=545 ; n=265$ for boys; $n=280$ for girls.

a subject area-by-gender interaction, $F(2,542)=6.78, p<0.001$. Together these results indicate that, although there was a difference in the mean level of task value across subject areas with mathematics generally higher than the other two areas contrary to our expectations (see Table 1), the pattern of these mean differences across subject areas varied for males and females.

The post hoc Scheffe tests indicated that males reported greater levels of task value in mathematics than in English $(p<0.05)$, and social studies $(p<0.05)$. However, there was no difference in the task value expressed for English and social studies $(p<0.05)$ for males. Females, as expected from the significant interaction effect, expressed a somewhat different pattern of means. Females reported a higher mean level of task value in mathematics than in either English $(p<0.05)$ or social studies $(p<0.05)$. Unlike males, 
females also reported a higher level of task value in English than in social studies $(p<0.05)$.

Self-efficacy. The repeated measures ANOVA examining self-efficacy indicated an effect for subject area, $F(2,542)=6.90, p<0.001$, and a significant interaction between subject area and gender, $F(2,542)=16.57, p<0.001$, but no effect for gender, $F(1,543)=2.07, p>0.10$. The main effect for subject area was consistent with our hypothesis and showed that self-efficacy was highest in English compared to mathematics and social studies, but this effect was conditional on a gender by subject area interaction. The post hoc Scheffe tests indicated that males reported similar levels of self-efficacy across all three subject areas. That is, the differences between mathematics, English, and social studies all failed to reach significance (see Table 1). In contrast, females reported, on average, higher levels of self-efficacy in English than in mathematics $(p<0.05)$ or social studies $(p<0.05)$. Females' self-efficacy in mathematics and social studies was similar.

Test anxiety. Results for students' level of test anxiety indicated a main effect for subject area, $F(2,542)=58.06, p<0.001$, a main effect for gender, $F(1,543)=10.82, p<0.001$, as well as an interaction between gender and subject area, $F(2,542)=14.39, p<0.001$. The main effect for subject area showed that anxiety was highest in social studies followed by mathematics and then English. However, the gender-by-subject area interaction indicated that males reported less anxiety in English than in social studies $(p<0.05)$, whereas there was no difference in the test anxiety reported by males in mathematics and English, or between mathematics and social studies (see Table 1). Females reported feeling less anxious in English than in mathematics $(p<0.05)$ or social studies $(p<0.05)$. Also, females were less anxious in mathematics than in social studies $(p<0.05)$.

Cognitive strategy use. For students' use of cognitive strategies there was a main effect of subject area, $F(2,542)=17.96, p<0.001$, and a main effect of gender, $F(1,543)=5.13, p<0.05$. However, unlike the motivational outcomes, the subject area-by-gender interaction did not reach significance, $F(2,542)=0.13, p>0.10$. Hence, the relationship among subject areas was similar for males and females and the Scheffe post hoc tests were computed across all students. Summing across both males and females these tests indicated that, on average, students reported greater cognitive strategy use in social studies than in mathematics $(p<0.05)$, or English $(p<0.05)$. Moreover, students reported greater levels of strategy use in English than in mathematics $(p<0.05)$. These findings were consistent with our hypotheses. 
Self-regulation. With respect to students' use of regulatory strategies, the main effects of subject area, $F(2,542)=0.65, p>0.10$, and gender, $F(1,543)$ $=0.12, p>0.10$, and the subject area by gender interaction, $F(2,542)=2.62$, $p>0.05$, all failed to reach significance. Hence, both males and females, on average, reported similar levels of regulatory strategy use across all three subject areas, contrary to our hypotheses.

Classroom performance. Finally, analyses examining mean level differences in students' grades were completed. Although these analyses indicated no effect of subject area, $F(2,542)=0.08, p>0.10$, as would be expected given that we standardized within teachers, and no interaction of subject area and gender, $F(2,542)=1.46, p>0.05$, there was a significant main effect of gender, $F(1,543)=6.50, p<0.05$. On average, across all subject areas, females received higher grades than males (see Table 1).

\section{Subject area differences in relations among variables}

While results from these mean level analyses are helpful for examining differences in the level of motivational, strategy use and performance measures across subject areas, they do not provide any information about the relations among these constructs, or about how these relations might differ among the subject areas. In order to explore the relations among the motivational, strategy use, and performance variables, we next computed the zero-order correlations among variables within the same subject area.

Table 2 presents the zero-order correlations among the motivational, strategy use and performance variables within and across the subject areas of mathematics, English, and social studies. Results from these analyses indicate significant relations among many of the variables within each subject area that parallel previous findings (Pintrich \& De Groot, 1990). Within each subject area, the strongest correlation was between the two strategy use variables, with $r=0.66,0.67$ and 0.67, $p$ 's $<0.001$, in mathematics, English, and social studies, respectively. More importantly, the pattern of the relations across the three subject areas was similar, suggesting very little in the way of domain differences in the relations. The correlations among the same constructs across different subject areas were all positive and significant (see Table 2). The correlations among the cognitive strategy use and regulatory strategy use variables across subject areas were especially large ( $r$ 's between 0.85 and 0.90 ), indicating that students tended to report similar levels of strategy use across all three domains.

In order to address our second research question further, we next computed a series of multivariate regression analyses. More specifically, we computed a separate regression equation to predict cognitive strategy use, regulatory 


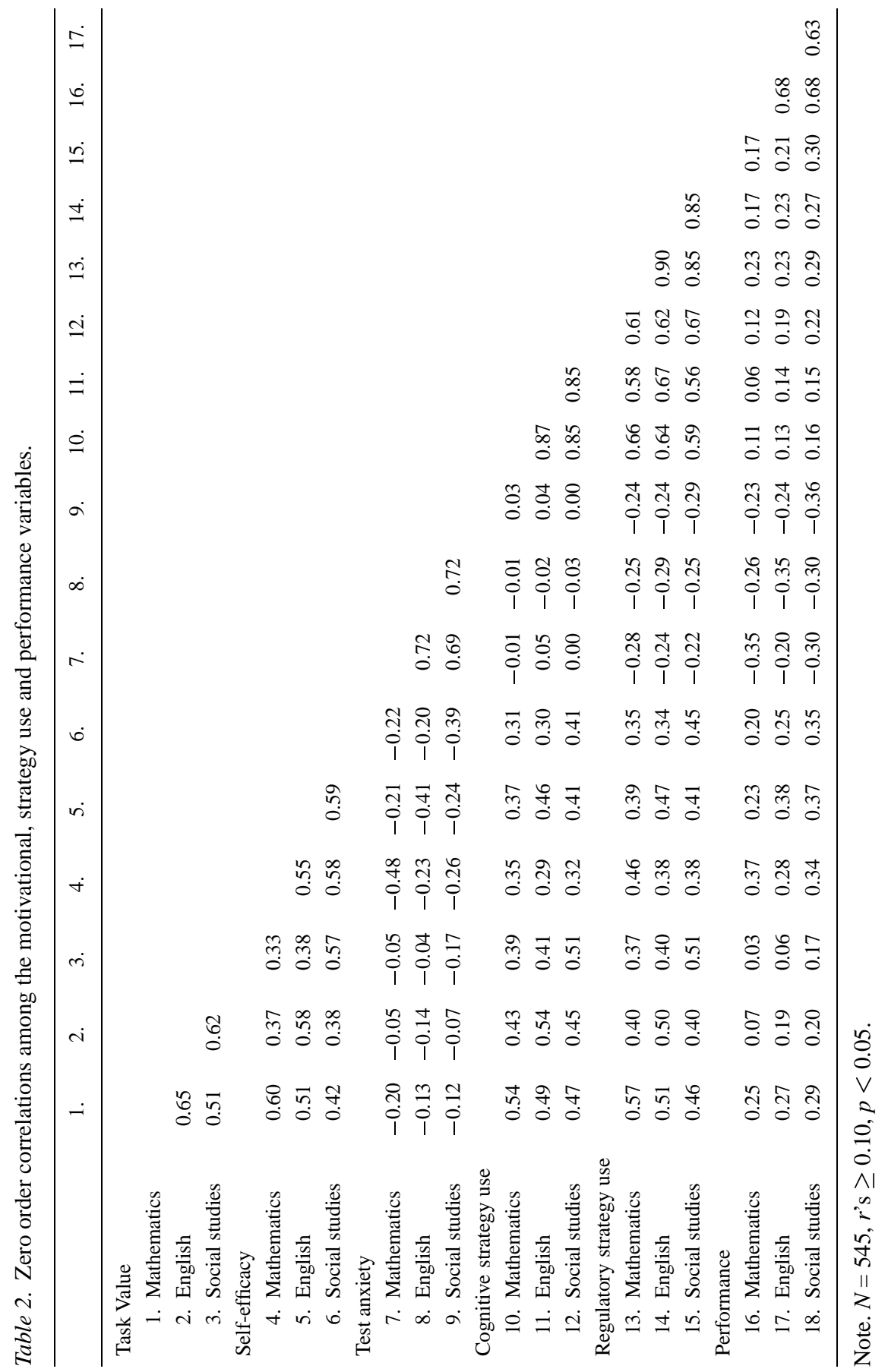


Table 3. Summary of regression analyses for variables predicting cognitive strategy use, regulatory strategy use, and performance in mathematics, English and social studies $(\mathrm{N}=$ $545)$.

\begin{tabular}{|c|c|c|c|c|c|c|c|c|c|}
\hline \multirow[b]{2}{*}{ Variable } & \multicolumn{3}{|c|}{ Mathematics } & \multicolumn{3}{|c|}{ English } & \multicolumn{3}{|c|}{ Social Studies } \\
\hline & $B$ & $S E B$ & $\beta$ & $B$ & $S E B$ & $\beta$ & $B$ & $S E B$ & $\beta$ \\
\hline \multicolumn{10}{|c|}{ Cognitive strategy use } \\
\hline Gender & 0.20 & 0.08 & $0.08^{*}$ & 0.17 & 0.08 & $0.07^{*}$ & 0.27 & 0.08 & $0.12^{* *}$ \\
\hline Task value & 0.53 & 0.05 & $0.49^{* * *}$ & 0.40 & 0.04 & $0.39^{* * *}$ & 0.36 & 0.04 & $0.40^{* * *}$ \\
\hline Self-efficacy & 0.13 & 0.05 & $0.13^{* *}$ & 0.33 & 0.05 & $0.30^{* * *}$ & 0.23 & 0.04 & $0.25^{* * *}$ \\
\hline Test anxiety & 0.10 & 0.03 & $0.14^{* * *}$ & 0.13 & 0.03 & $0.16^{* * *}$ & 0.10 & 0.03 & $0.15^{* * *}$ \\
\hline $\mathrm{R}^{2}$ & & & $0.31^{* * *}$ & & & $0.36^{* * *}$ & & & $0.32^{* * *}$ \\
\hline \multicolumn{10}{|c|}{ Regulatory strategy use } \\
\hline Gender & 0.04 & 0.08 & 0.02 & 0.01 & 0.08 & 0.00 & 0.10 & 0.08 & 0.04 \\
\hline Task value & 0.48 & 0.04 & $0.47^{* * *}$ & 0.36 & 0.04 & $0.36^{* * *}$ & 0.35 & 0.04 & $0.39^{* * *}$ \\
\hline Self-efficacy & 0.11 & 0.04 & $0.11^{*}$ & 0.20 & 0.05 & $0.19^{* * *}$ & 0.14 & 0.04 & $0.16^{* * *}$ \\
\hline Test anxiety & -0.09 & 0.03 & $-0.13^{* * *}$ & -0.12 & 0.03 & $-0.16^{* * *}$ & -0.12 & 0.03 & $-0.17^{* * *}$ \\
\hline $\mathrm{R}^{2}$ & & & $0.36^{* * *}$ & & & $0.32^{* * *}$ & & & $0.32^{* * *}$ \\
\hline \multicolumn{10}{|c|}{ Academic performance } \\
\hline Gender & 0.26 & 0.07 & $0.13^{* * *}$ & 0.24 & 0.07 & $0.13^{* * *}$ & 0.28 & 0.07 & $0.15^{* * *}$ \\
\hline Task value & 0.04 & 0.04 & 0.04 & 0.02 & 0.04 & 0.02 & -0.02 & 0.04 & -0.02 \\
\hline Self-efficacy & 0.18 & 0.04 & $0.23^{* * *}$ & 0.22 & 0.05 & $0.25^{* * *}$ & 0.20 & 0.04 & $0.26^{* * *}$ \\
\hline Test anxiety & -0.15 & 0.03 & $-0.25^{* * *}$ & -0.16 & 0.03 & $-0.25^{* * *}$ & -0.15 & 0.02 & $-0.26^{* * *}$ \\
\hline $\mathrm{R}^{2}$ & & & $0.19^{* * *}$ & & & $0.20^{* * *}$ & & & $0.18^{* * *}$ \\
\hline
\end{tabular}

Note. ${ }^{*} \mathrm{p}<0.05 ;{ }^{* *} \mathrm{p}<0.01 ;{ }^{* * *} \mathrm{p}<0.001$. For gender, $0=$ boys, $1=$ girls.

$\mathrm{B}=$ unstandardized beta, $\mathrm{SE} \mathrm{B}=$ standard error of $\mathrm{B} . \beta=$ standardized beta.

strategy use and classroom performance within each subject area. We followed the general strategy of Pintrich \& De Groot (1990) by using the motivational beliefs to predict the cognitive outcomes. Independent variables for these nine equations (three each in mathematics, English, and social studies) were gender (dummy-coded), task value, self-efficacy, and test anxiety assessed with respect to each specific subject area. Initially, we also included the three cross-product terms for the interactions between gender and each of the three motivational predictors to check for gender by motivation interactions. None of these interactions was significant, so they were dropped from the final analyses and are not reported. Results from these final regression analyses are presented in Table 3, and will be discussed first for cognitive strategy use, then regulatory strategy use, and finally for classroom performance. 
Cognitive strategy use. Gender, task value, self-efficacy, and test anxiety together accounted for a significant portion of the variance in cognitive strategy use in mathematics, $F(4,540)=61.66, p<0.001$, English, $F(4,540)$ $=75.12, p<0.001$, and social studies, $F(4,540)=62.77, p<0.001$. As presented in Table 3, task value had the greatest individual standardized coefficient in the analyses predicting cognitive strategy use in mathematics, English and social studies. This variable uniquely explained between 15\% (English) and 24\% (mathematics) of the variance in cognitive strategy use, with greater task value predicting greater use of cognitive strategies. In other words, students who valued and were interested in the subject area reported higher levels of cognitive strategy use in each of the three subjects examined. Self-efficacy and test anxiety also were both significant individual predictors of students' cognitive strategy use in all three subject areas, although to a somewhat lesser degree than task value. After accounting for the other variables in the analyses, self-efficacy uniquely explained between $2 \%$ (mathematics) and 9\% (English) of the variance in cognitive strategy use, whereas test anxiety uniquely explained approximately $2 \%$ of the variance in cognitive strategy use across all three subject areas. In mathematics, English, and social studies, students who reported greater self-efficacy and higher levels of test anxiety were more likely to report using cognitive strategies than students who were less efficacious and less anxious. Finally, the standardized coefficient for gender was also significant although this variable uniquely explained less than $1 \%$ of the variance in strategy use in each of the three subjects examined after accounting for differences in the three motivational variables. Generally, females reported using cognitive strategies more often than males within each of the three subject areas (see Table 3).

Regulatory strategy use. Gender, task value, self-efficacy, and test anxiety together accounted for approximately one-third of the variance in regulatory strategy use in mathematics, $F(4,540)=74.81, p<0.001$, English, $F(4,540)$ $=63.87, p<0.001$, and social studies, $F(4,540)=63.87, p<0.001$. Task value was the single best predictor of regulatory strategy in all three subject areas. This variable alone uniquely explained between $13 \%$ (English) and $22 \%$ (mathematics) of the variance in students' reported use of regulatory strategies (see Table 3). Across all three subject areas, students who reported greater task value for the subject area reported using regulatory strategies more often than students with lower task value. The significant coefficients for self-efficacy and test anxiety indicated that these variables also were important predictors of regulatory strategy use. After accounting for the other variables in the analyses, self-efficacy uniquely explained between $1 \%$ (mathematics) and $4 \%$ (English) of the variance in regulatory strategy use (see Table 3 ). 
Similarly, test anxiety by itself explained between $2 \%$ (mathematics) and $3 \%$ (social studies) of the variance in regulatory strategy use (see Table 3 ). However, while greater levels of self-efficacy were associated with greater reported use of regulatory strategies, students who reported higher levels of test anxiety were less likely to report engaging in regulatory strategy use across all three subject areas. The standardized coefficient for gender was non-significant in mathematics, English, and social studies.

Performance. With respect to classroom performance, the four predictors together explained a significant amount of the variance in classroom performance in mathematics, $F(4,540)=31.04, p<0.001$, English, $F(4,540)=$ $33.99, p<0.001$, and social studies, $F(4,540)=30.61, p<0.001$. Unlike the strategy use equations, the standardized regression coefficient for task value indicated that this variable was a non-significant predictor of classroom performance in each of the three subject areas studied (see Table 3). The standardized regression coefficients for both self-efficacy and test anxiety, however, were each significant in mathematics, English and social studies. Selfefficacy, by itself, explained approximately $6 \%$ of the variance in classroom grade, even after accounting for students' gender, task value, and level of test anxiety. Similarly, test anxiety uniquely explained approximately $6 \%$ of the variance in classroom grade in mathematics, English and social studies (see Table 3). In all three subject areas, students with greater self-efficacy, on average, received higher classroom grades than students with lower self-efficacy. In contrast, students who reported higher levels of test anxiety received lower grades than students who were less anxious (see Table 3).

\section{Discussion}

This study investigated contextual differences in motivation and selfregulated learning in three different subject areas. With respect to our first research question concerning mean level differences, our findings provide evidence that the motivational aspects of self-regulated learning are, to some degree, context specific. In particular, we found differences in students' reported value and interest for academic tasks, self-efficacy, and test anxiety across the academic subject areas of mathematics, English, and social studies. Moreover, as suggested in our third research question, the nature of these mean level difference was moderated by gender for each of the three motivational constructs examined.

In terms of students' reported value or interest in classroom tasks, students tended to view mathematics as more important, useful and interesting than either English or social studies. Both males and females rated mathematics 
as the most important, useful, and interesting subject overall. However, there were gender differences in terms of comparisons between social studies and English. For males, English and social studies were perceived in the same way in terms of value and interest, whereas for females, English was rated as more important than social studies (although not as highly as mathematics). These results parallel the findings of Eccles and Wigfield and their colleagues (Eccles, 1983, 1984; Eccles et al. 1989; Wigfield et al., 1991; Wigfield \& Eccles, 1994) where males and females did not differ in terms of their liking and value for mathematics, but that males usually find English (or reading, in the studies of young elementary children, e.g., Wigfield \& Eccles, 1994) as less interesting and important. The consistency in these findings for task value and interest across a number of different studies of both elementary and secondary students suggests that any difficulties females may have in mathematics is not due to variations in their liking or value for mathematics.

However, our results do show that females are less likely to have adaptive levels of efficacy and anxiety in mathematics. In particular, males reported similar levels of self-efficacy across all subject areas, whereas females reported higher levels of self-efficacy in English than in either mathematics or social studies. Finally, with respect to test anxiety, males reported similar levels of test anxiety in mathematics and English, while females reported lower levels of anxiety in English than in mathematics. Again, our results are in line with previous findings of the gender differences in efficacy and competence beliefs for mathematics and English (Eccles, 1983, 1984; Wigfield \& Eccles, 1994) suggesting that females do not have as adaptive efficacy beliefs as males. This is particularly troublesome as our results and the work of Eccles and Wigfield and their colleagues also show that there are few gender differences in actual classroom performance or achievement. In fact, in our study, females received higher average grades than males in all three subject areas. This "lack of calibration" (lack of a good match between efficacy beliefs and actual achievement) is a consistent pattern in the research on gender differences with females traditionally underestimating their competence and efficacy relative to their performance in comparison to males (see Phillips \& Zimmerman, 1990; Pintrich \& Schunk, 1996). Accordingly, any problems females might experience in mathematics seem more likely to stem from less adaptive efficacy and anxiety beliefs than lack of value or interest.

At the same time, it appears that these gender differences in efficacy and anxiety beliefs do not necessarily result in less cognitive strategy use or selfregulation for females. In terms of cognitive strategy use, we found differences in the level of cognitive strategy use across subject areas as predicted. As a group, students reported higher levels of cognitive strategy use in social studies than in English or mathematics, and higher levels in English than in 
mathematics. In addition, females reported higher levels of cognitive strategy use than males across all three subjects. In contrast and against predictions, the reported level of regulatory strategy use was similar among all subject areas for both males and females. Hence, while students tended to report using more cognitive strategies in social studies, they did not report regulating their learning in social studies any more than in mathematics or English. Of course, given that we standardized grades within teachers, there were no differences by subject area in academic performance.

The finding that students report greater cognitive strategy use in social studies fits neatly with the work of Stodolsky and Grossman (Grossman \& Stodolsky, 1994, 1995; Stodolsky, 1988) who found that social studies classrooms might offer more diverse and engaging tasks than mathematics classrooms. Taken together, our results on student reports of cognitive strategy use and Stodolsky and Grossman's results on disciplinary differences suggest that the level of self-regulated learning in terms of strategy use can vary as a function of subject area differences in classroom context. Of course, a definitive conclusion awaits studies that combine observation of disciplinary differences in actual classroom tasks and instruction as well as concomitant differences in the level of students' self-regulated learning. Nevertheless, it seems that level of cognitive strategy use can be sensitive to contextual differences and there is a need for future research to investigate how the different dimensions of the classroom and academic disciplines are linked to self-regulated learning as suggested by Zimmerman (1994).

With respect to our second research question, we found very similar relations among the motivational, strategy use, and performance outcomes across subject areas. Both the correlational and regression analyses indicated that the relations among students' task value, self-efficacy, test anxiety, cognitive strategy use, regulatory strategy use and performance were similar for mathematics, English and social studies. For example, the amount of variance explained by the motivational variables and gender in students' cognitive strategy use, regulatory strategy use and performance were very similar across all three subject areas. Further, in all of the analyses there were no differences in terms of which predictors were significant across subject areas. In mathematics, English, and social studies, task value was the best individual predictor of both cognitive and regulatory strategy use, whereas task value was not a significant predictor of classroom performance. As we have found in other studies (Pintrich \& De Groot, 1990; Pintrich et al., 1994) students who valued and were interested in the content of the subject area were more likely to report using deeper processing strategies and more self-regulatory strategies. Paralleling findings from many different studies (see Pintrich \& 
Schrauben, 1992 for review), students were more deeply cognitively engaged in learning when their interest and value were high.

In contrast, task value was not a significant predictor of actual performance in comparison to self-efficacy. Self-efficacy predicted both strategy use variables as well as classroom performance similarly in all three subject areas. Students who felt they were capable of learning and understanding the material and expected to do well were more likely to report using a variety of cognitive and self-regulatory strategies. In addition, they also received higher grades. This finding that efficacy predicts actual performance and task value does not, although both predict strategy use, is consistent with previous findings (Pintrich \& De Groot, 1990). It appears that task value is related to the initial "choice" of becoming involved in academic tasks in terms of higher levels of cognitive strategy use and self-regulation, but in terms of the ultimate outcome of grades, self-efficacy is more important, as well as actual strategy use (Pintrich \& De Groot, 1990).

From a social cognitive and self-regulated learning perspective, it appears that interest and value can help a student choose to become involved in a task, somewhat like a "starter" for a car, but once involved, the self-regulation processes of strategy use and adaptive efficacy beliefs are more important for "steering" and controlling actual performance (cf., Garcia \& Pintrich, 1994; Schunk, 1994; Zimmerman, 1994). Similar to this interpretation, results from studies in an expectancy-value framework (see Eccles, 1983; Wigfield, 1994; Wigfield \& Eccles, 1992, 1994) consistently reveal that task value is related to the choice of taking additional courses in a subject area, but once actually enrolled in a specific course, task value beliefs do not predict course achievement, while efficacy and competence beliefs do predict actual achievement. Although more microgenetic research is needed to investigate the relations between task value, efficacy and self-regulation processes in "real-time" as students actually learn (see Butler \& Winne, 1995), the results seem to be reliable and consistent across a number of different studies from different theoretical frameworks.

Although test anxiety was also an important predictor of both strategy use and performance in similar ways across subject areas, it was related to cognitive strategy use differently than it was to regulation and performance. In particular, students who reported higher levels of test anxiety were more likely to engage in cognitive strategies, but were less likely to use regulatory strategies and tended to receive lower grades. This finding is consistent with previous work in a social cognitive framework (Pintrich \& De Groot, 1990). Students who are anxious may use more cognitive strategies in an attempt to do better, but they have difficulties in regulating their learning and often end up performing more poorly (Bandura, 1986; Pintrich \& Schunk, 1996). 
In summary, these finding provide some evidence that the relations among motivational, strategy use, and performance measures are similar across subject areas. However, the current study did not test the similarity of these relations directly and additional work is needed to replicate these findings. Another caveat to these findings is that the relatively stronger relations between the motivational and strategy use constructs as compared to the relation between motivational and performance measures might be due to the nature in which these different factors were assessed. Both the motivational and strategy use variables were measured using student self-reports, whereas academic performance was collected using school grades. Hence, the strong relations between the motivational and strategy use variables might be inflated somewhat because they are all based on students' self-reports.

Nonetheless, the current findings show that students may report mean level differences in the motivational and cognitive components of self-regulated learning across different academic contexts, but that the relations among these components are similar across contexts. That is, the level and quality of student motivation or cognition for a subject area may vary, but the pattern of the relations between motivation and cognition seems robust across subject areas. Of course, the generalizability of this study is limited by only including 17 teachers across the three subject areas. Future research will have to examine the reliability of the subject area mean level differences we found by including more teachers within each subject area. In addition, as noted above, actual data on the nature of the classroom context and instructional activities will be important to tease apart subject area differences from general instructional differences. Further, research which employed observational or on-line assessments of motivation and strategy use would provide support for the current conclusions. Nevertheless, our findings on the similarity of the relations between motivation and cognition across subject areas suggest that the general models of self-regulated learning that are being developed are applicable to different academic domains and can be fruitfully used to understand student learning in different classroom contexts.

\section{Note}

1. Although students were asked about science, the data for science were not included in the present study because half of the students were not currently enrolled in a specific science class when the questionnaire was administered. In this school eighth graders only took science for one semester out of the two semesters with half the sample taking it first semester and the other half taking it second semester. 


\section{References}

Ames, C. (1992). Classrooms: Goals, structures, and student motivation. Journal of Educational Psychology 84: 261-271.

Bandura, A. (1986). Social Foundations of Thought and Action: A Social Cognitive Theory. Englewood Cliffs, NJ: Prentice-Hall.

Brown, A., Bransford, J., Ferrara, R. \& Campione, J. (1983). Learning, remembering, and understanding. In P. Mussen, ed. (Series), and J. Flavell \& E. Markman, eds. (Vol), Handbook of Child Psychology: Vol. 3. Cognitive Development (pp. 77-166). New York: Wiley.

Butler, D. \& Winne, P. (1995). Feedback and self-regulated learning: A theoretical synthesis. Review of Educational Research 65: 245-281.

Corno, L. (1989). Self-regulated learning: A volitional analysis. In B.J. Zimmerman \& D.H. Schunk, eds., Self-Regulated Learning and Academic Achievement: Theory, Research, and Practice (pp. 111-141). New York: Springer-Verlag.

Cohen, E. (1994). Restructuring the classroom: Conditions for productive small groups. Review of Educational Research 64: 1-35.

Doyle, W. (1983). Academic work. Review of Educational Research 53: 159-199.

Eccles, J.S. (1983). Expectancies, values, and academic behavior. In J.T. Spence, ed., Achievement and Achievement Motives (pp. 75-146). San Francisco: Freeman.

Eccles, J.S. (1984). Sex differences in achievement patterns. In T. Sonderegger, ed., Nebraska Symposium on Motivation, Vol. 32 (pp. 97-132). Lincoln, NE: University of Nebraska Press.

Eccles, J.S., Wigfield, A., Flanagan, C., Miller, C., Reuman, D. \& Yee, D. (1989). Self-concepts, domain values, and self-esteem: Relations and changes at early adolescence. Journal of Personality 57: 283-310.

Garcia, T. \& Pintrich, P.R. (1994). Regulating motivation and cognition in the classroom: The role of self-schemas and self-regulatory strategies. In D.H. Schunk \& B.J. Zimmerman, eds., Self-Regulation of Learning and Performance: Issues and Educational Applications (pp. 127-153). Hillsdale, NJ: Lawrence Erlbaum Associates.

Grossman, P. \& Stodolsky, S. (1994). Considerations of content and the circumstances of secondary school teaching. In L. Darling-Hammond, ed., Review of Research in Education, Vol. 20 (pp. 179-221). Washington, DC: American Educational Research Association.

Grossman, P. \& Stodolsky, S. (1995). Content as context: The role of school subjects in secondary teaching. Educational Researcher 24(8): 5-11.

Maehr, M.L. \& Midgley, C. (1991). Enhancing student motivation: A schoolwide approach. Educational Psychologist 26: 399-427.

Meece, J., Blumenfeld, P. \& Hoyle, R. (1988). Students' goal orientation and cognitive engagement in classroom activities. Journal of Educational Psychology 80: 514-523.

Phillips, D. \& Zimmerman, M. (1990). The developmental course of perceived competence and incompetence among competent children. In R.J. Sternberg \& J. Kolligian, eds., Competence Considered (pp. 41-66). New Haven, CT: Yale University Press.

Pintrich, P.R. \& De Groot, E. (1990). Motivational and self-regulated learning components of classroom academic performance. Journal of Educational Psychology 82: 33-40.

Pintrich, P.R. Roeser, R. \& De Groot, E. (1994). Classroom and individual differences in early adolescents' motivation and self-regulated learning. Journal of Early Adolescence 14: 139-161.

Pintrich, P.R. \& Schrauben, B. (1992). Students' motivational beliefs and their cognitive engagement in classroom tasks. In D.H. Schunk \& J. Meece, eds., Student Perceptions in the Classroom: Causes and Consequences (pp. 149-183). Hillsdale, NJ: Lawrence Erlbaum Associates.

Pintrich, P.R. \& Schunk, D.H. (1996). Motivation in Education: Theory, Research, and Applications. Englewood Cliffs, NJ: Merrill Prentice-Hall. 
Pintrich, P.R., Smith, D.A.F., Garcia, T. \& McKeachie, W.J. (1993). Reliability and predictive validity of the Motivated Strategies for Learning Questionnaire (MSLQ). Educational and Psychological Measurement 53: 801-813.

Schneider, W. \& Pressley, M. (1989). Memory Development Between 2 and 20. New York: Springer-Verlag.

Schunk, D.H. (1989). Self-efficacy and achievement behaviors. Educational Psychology Review 1, 173-208.

Schunk, D.H. (1991). Self-efficacy and academic motivation. Educational Psychologist 26: 207-231.

Schunk, D.H. (1994). Self-regulation of self-efficacy and attributions in academic settings. In D.H. Schunk \& B.J. Zimmerman, eds., Self-Regulation of Learning and Performance: Issues and Educational Applications (pp. 75-99). Hillsdale, NJ: Lawrence Erlbaum Associates.

Siegler, R.S. (1988). Individual differences in strategy choices: Good students, not-so-good students, and perfectionists. Child Development 59: 833-851.

Sternberg, R.J. (1988). The Triarchic Mind: A New Theory of Human Intelligence. New York: Viking.

Sternberg, R.J. (1994). PRSVL: An integrative framework for understanding mind in context. In R.J. Sternberg \& R.K. Wagner, eds., Mind in Context: Interactionist Perspectives on Human Intelligence (pp. 218-232). New York: Cambridge University Press.

Stodolsky, S. (1988). The Subject Matters: Classroom Activity in Math and Social Studies. Chicago: The University of Chicago Press.

Stodolsky, S. \& Grossman, P. (1995). The impact of subject matter on curricular activity: An analysis of five academic subjects. American Educational Research Journal 32: 227-249.

Stodolsky, S., Salk, S. \& Glaessner, B. (1991). Student views about learning math and social studies. American Educational Research Journal 28: 89-116.

Weinstein, C.E. \& Mayer, R. (1986). The teaching of learning strategies. In M.C. Wittrock, ed., Handbook of Research on Teaching (pp. 315-327). New York: Macmillan.

Wigfield, A. (1994). Expectancy-value theory of achievement motivation: A developmental perspective. Educational Psychology Review 6: 49-77.

Wigfield, A. \& Eccles, J.S. (1989). Test anxiety in elementary and secondary school students. Educational Psychologist 24: 159-183.

Wigfield, A. \& Eccles, J.S. (1992). The development of achievement task values: A theoretical analyses. Developmental Review 12: 265-310.

Wigfield, A. \& Eccles, J.S. (1994). Children's competence beliefs, achievement values, and general self-esteem change across elementary and middle school. Journal of Early Adolescence 14: 107-138.

Wigfield, A., Eccles, J.S., MacIver, D., Reuman, D. \& Midgley, C. (1991). Transitions at early adolescence: Changes in children's domain-specific self-perceptions and general self-esteem across the transition to junior high school. Developmental Psychology 27: $552-565$.

Zimmerman, B.J. (1989). Models of self-regulated learning and academic achievement. In B.J. Zimmerman \& D.H. Schunk, eds., Self-Regulated Learning and Academic Achievement: Theory, Research, and Practice (pp. 1-25). New York: Springer-Verlag.

Zimmerman, B.J. (1994). Dimensions of academic self-regulation: A conceptual framework for education. In D.H. Schunk \& B.J. Zimmerman, eds., Self-Regulation of Learning and Performance: Issues and Educational Applications (pp. 3-21). Hillsdale, NJ: Lawrence Erlbaum Associates.

Zimmerman, B.J. \& Martinez-Pons, M. (1990). Student differences in self-regulated learning: Relating grade, sex, and giftedness to self-efficacy and strategy use. Journal of Educational Psychology 82: 51-59. 